\title{
Phylogenetic Analysis of Some Aerococcus-Like Organisms from Clinical Sources: Description of Helcococcus kunzii
}

\author{
gen. nov., sp. nov. \\ MATTHEW D. COLLINS, ${ }^{1}$ RICHARD R. FACKLAM, ${ }^{2}$ UBALDINA M. RODRIGUES, ${ }^{1}$ \\ AND KATHRYN L. RUOFF ${ }^{3 *}$ \\ AFRC Institute of Food Research, Reading Laboratory, Reading RG6 2EF, United Kingdom ${ }^{1}$; \\ Centers for Disease Control, Atlanta, Georgia $30333^{2}$; and Massachusetts \\ General Hospital, Boston, Massachusetts 02114
}

\begin{abstract}
$16 S$ rRNA gene sequencing studies were performed on some unusual gram-positive catalase-negative cocci of unknown taxonomic position isolated from human clinical sources. Comparative analysis of the sequence data demonstrated that the clinical isolates represent a hitherto-unknown line of descent within the low-G+Ccontent gram-positive bacteria. On the basis of the phylogenetic findings and the phenotypic distinctiveness of the organisms, it is proposed that they be classified in a new genus, Helcococcus, as Helcococcus kunzii sp. nov. The type strain of $H$. kunzii is NCFB 2900.
\end{abstract}

A collection of nine strains of a gram-positive coccoid organism isolated from human sources appeared to represent a previously undescribed bacterial group. The strains, catalase-negative facultative anaerobes showing some phenotypic resemblance to Aerococcus viridans, were all isolated from wound cultures. Seven of the strains were recovered from lower-extremity wounds (six from feet and one from a lower-leg ulcer); the remaining isolates were found in cultures of breast masses. Most cultures were mixed, containing organisms such as staphylococci in addition to the aerococcus-like strains. However, these isolates differed from typical aerococci by virtue of their variable growth in $6.5 \% \mathrm{NaCl}$ and their lipophilic nature, as evidenced by the stimulation of their growth by horse serum or Tween 80 . Their slow growth and small colony size may have precluded their recognition in mixed cultures containing other more vigorously growing bacterial strains.

16S rRNA is universally recognized as a powerful molecular chronometer. Different degrees of sequence conservation (ranging from very conserved to highly variable) enable the molecule to measure small genealogical distances as well as span great ones (25). Over the past few years, 16S rRNA sequencing studies have greatly improved the taxonomy of the genera Aerococcus, Enterococcus, Lactococcus, and Streptococcus and other catalase-negative lactic acid bacteria $(2-4,6,21,24)$. 16S rRNA sequence comparisons have not only proved invaluable in clarifying the inter- and intrageneric relationships among these taxa, but because of the cumulative nature of the sequence data, they have also provided a firm basis for the recognition of several new species and genera $(1,3,5,6,21-23)$. Therefore, in the present study we have further characterized these unusual cocci from human clinical sources, using phenotypic tests and partial 16S rRNA sequencing. On the basis of phylogenetic analysis and the phenotypic distinctiveness of these organisms, we propose that they be classified in a new genus, Helcococcus.

\footnotetext{
${ }^{*}$ Corresponding author.
}

\section{MATERIALS AND METHODS}

DNA studies. Chromosomal DNA was isolated as described by Pitcher et al. (18). DNA base composition was estimated by thermal denaturation in standard saline citrate as described by Garvie (13), with DNA from Escherichia coli NCDO 1984 (K-12) (51.5 mol\% G+C) as the standard. Chromosomal DNA hybridization studies were performed as described by Farrow et al. (10).

$16 S$ rRNA gene sequence determination and analysis. Approximately $2.5 \mu \mathrm{g}$ of DNA was subjected to polymerase chain reaction amplification in a total volume of $100 \mu \mathrm{l}$ containing $2 \mathrm{U}$ of Taq polymerase (Amersham International, Aylesbury, United Kingdom). The reaction involved 36 cycles of denaturation at $92^{\circ} \mathrm{C}$ for $2 \mathrm{~min}$, primer annealing at $55^{\circ} \mathrm{C}$ for $1 \mathrm{~min}$, and primer extension at $72^{\circ} \mathrm{C}$ for $1.5 \mathrm{~min}$. DNA was extracted with chloroform and purified with a Geneclean II kit (Bio 101, Inc.) according to the manufacturer's instructions. Qualitative analysis of the DNA fragments was performed by agarose gel electrophoresis. The amplified product was sequenced by using $\alpha-{ }^{35}$ S-dATP and a Sequenase version 2.0 sequencing kit (U.S. Biochemicals) as described previously (15). Reaction products were separated on 55 -cm-long wedge-shaped ( 0.2 to 0.6 -mm-thick) $6 \%$ acrylamide-7 M urea gels at $55^{\circ} \mathrm{C}$ using an LKB Macrophor 2010 sequencing unit operated at $50 \mathrm{~W}$ per gel.

Sequences were aligned and similarity values were determined by using the Wisconsin Molecular Biology package (7). Nucleotide substitution rates $\left(K_{\text {nuc }}\right.$ values) were calculated, and an unrooted phylogenetic tree was produced by using the algorithm of Fitch and Margoliash (12) contained in a program written by Felsenstein (11).

Biochemical tests. Isolates were routinely grown on brucella agar containing horse blood (Becton Dickinson Microbiology Systems, Cockeysville, Md.), which yielded inocula for biochemical tests. The strains were examined with the API 20 Strep system (Analytab Products, Plainview, N.Y.) and by conventional methods. The following media, obtained from BBL, Cockeysville, Md., were supplemented with horse serum (Bio-Whittaker, Walkersville, Md.) and used to examine the isolates: Andrade's broths containing glucose, maltose, sucrose, mannitol, and xylose; nitrate broth; urea agar; nutrient gelatin; motility test medium; and 
GAGAGUUUGAUCCUGGCUCAGGACGAACGCUGGCGGCGUGCUUAACACAU'GCAAGUUGAACGAGAAUUUUUCAGUUGAUUUCUUCGGAAUGAAACCGAAA ANGGAAAGUAGCGAACGGGUGAGUAACACGUGAGAAACCUGCCUUUCACAAAGGGAUAGCCUCGGGAAACCGGGAUUAAUACCUUAUGAUACAUUAAUAU CGCAUGAUGUAAAUGAUGUAAAUGUUAAAGAAUUUCGGUGAAAGAUGGUCUCGCGUCUGAUUAGCUAGUUGGUAAGGUACUGGCUUACCAAGGCAACGAU CAGUAGCCGGAUUGAGAGGUUGAACGGCCACACUGGAACUGAGACACGGUCCAGACUCCUACGGGAGGCAGCAGUGGGGAAUUUUGCACAAUGGGGGAAA CCCUGAUGCAGCGACGCCGCGUGAACGAUGAAGGUCUUCGGAUUGUAAAGUUCUGUCCUUAGCGAAGAUAAUGACAGUAGCUAAGAAGCAAGCCCUGGCU AAAUACGUGCCAGCAGCCGCGGUAAUACGUAUGGGGCAAGCGUUGUCCGGAAUUAUUGGGCGUAAAGGGUANGUAGGCGGUUAAUUAAGUCUGAAUUUAA AGGCUGUGGCUCAACCACGGUUCGGUUUAGAAAACUGGUUAACUUGAGUAGAUGAGGGGAAAGUGGAAUUCCAUGUGUAGCGGUGAAAUGCGUAGAUAUA UGGAGGAACACCAGUGGCGAAGGCGACUUUCUAGAAUCUAACUGACGCUGAGAUACGAAGGCGUGGGUAGCAAACAGGAUUAGAUACCCUGGUAGUCCAC GCAGUAAACGAUGAGUGCUAGUUGUUGGGAGUCAAAUCUCAGUGACGCAGCUAACGCAUUAAGCACUCCGCCUGGGGAGUACGUACGCAAGUAUGAAACU CAAAGGAAUUGACGGGGACCCGCACAAGCAGCGGAGAUGUGGUUUAAUUCGAAGCAACGCGAAGAACCUUACCAAGGCUUGAAGGGANAUCCUAGAGAUA GGAUAGUCUUUUCGGAGACUUGUAUACAGGUGGUGCAUGGUUGUCGUCAGCUCGUGUCGUGAGAUGUUGGGUUAAGUCCCGUAACGAGCGCAACCCCUAU CUUUAGUUACUAGCGAGUAAAGUCGAGGACUCUAGAGAGACUGCCGGUGAUAAACCGGAGGAAGGUGGGGAUGACGUCAAAUCAUCAUGCCCUAUAUGUC UUGGGCUACACACGUGCUACAAUGGUCUGAACAAAGCGUAGCUACCUCGUGAGAGCAAGCGAAUCGCAUAAAACAGAUCUCAGUUCGGAUUGCAGGCUGC AACUCGCCUGCAUGAAGUCGGAGUUGCUAGUAAUCGUGGAUCAGAACGCCACGGAGAAUGCGUUCCCGGGUCUUGUACACACCGCCCGUCACACCAUGGG AGUUGGCAAUACCCGAAGUCGUCGAGCUAACCGUCAAGGAGGCAGACGCCGAAGGUUGGGUAGAU

FIG. 1. Nucleotide sequence of derived 16S rRNA of $H$. kunzii (NCFB 2900).

brain heart infusion (BHI) broth containing 6.5\% $\mathrm{NaCl}$. The method of Wong (26) was employed to assay the ability of the isolates to synthesize porphyrins. The strains were tested for pyrazinamidase production by using a slight modification of the method of Sulea et al. (20). All isolates were tested for susceptibility to vancomycin by using standard disk diffusion methods and blood-supplemented MuellerHinton agar (16). The effects of different atmospheres on growth were examined by streaking 1 drop of a saline suspension of the isolates onto replicate blood agar plates and then incubating them for $48 \mathrm{~h}$ in either $5 \% \mathrm{CO}_{2}$, an ambient atmosphere, or an anaerobic chamber. The plates were examined for overall colony growth and size of individual colonies.

Biochemical tests performed on three of the strains at the Centers for Disease Control were carried out by the methods of Facklam and Collins (9). Included were tests for growth in the presence of elevated $\mathrm{NaCl}$ concentrations; growth at 10 and $45^{\circ} \mathrm{C}$; acid production from trehalose, sorbitol, lactose, mannitol, sucrose, inulin, raffinose, glycerol, arabinose, salicin, melibiose, maltose, and sorbose; hydrolysis of arginine, starch, esculin, urea, and hippurate; motility; production of acetoin; and susceptibility to vancomycin.

Nucleotide sequence accession number. The determined 16S rRNA gene sequence has been deposited in GenBank under accession number X69837.

\section{RESULTS AND DISCUSSION}

Cells of the nine clinical isolates were coccoid in shape and formed pairs, short chains, or irregular groups. The strains were gram-positive, catalase-negative, facultative anaerobes that were susceptible to vancomycin and unable to synthesize porphyrin. Upon original examination, the isolates grew poorly (if at all) on BHI agar and broth. All the strains grew well, forming pinpoint colonies after $24 \mathrm{~h}$, on brucella agar supplemented with $5 \%$ horse blood. Horse serum $(1 \%)$ or Tween $80(0.1 \%)$ greatly stimulated their growth on BHI agar or in BHI broth. There was no discernible enhancement of growth in either increased $\mathrm{CO}_{2}$ or an anaerobic atmosphere; cultures incubated on blood agar for $48 \mathrm{~h}$ in different atmospheres showed equally good growth, forming tiny greyish colonies. Only two of the specimens yielding these isolates were cultured both aerobically and anaerobically, with only one specimen yielding the isolate in both incubation atmospheres. The anaerobic culture of the second specimen contained a mixture of anaerobic bacteria that may have overgrown the isolate in question. Seven of the nine strains produced the enzyme pyrazinamidase.

When tested with serum-supplemented Andrade's broths, the isolates produced acid from glucose and maltose, but they gave negative reactions in all other serum-supplemented media. The three strains examined at the Centers for Disease Control showed negative reactions in all tests performed, including the test for growth at 10 and $45^{\circ} \mathrm{C}$, with the exception of the test for hydrolysis of esculin. The strains tested at the Centers for Disease Control grew in media supplemented with 2.0 and $4.0 \% \mathrm{NaCl}$, but growth in the presence of $6.5 \% \mathrm{NaCl}$ was variable. When all strains were tested with serum-supplemented BHI broth containing $6.5 \%$ $\mathrm{NaCl}$, two of the nine isolates failed to grow after 7 days of incubation, and the remaining isolates showed a lag period before visible growth was noted.

All the isolates gave an API Rapid Strep profile of 4100413 , corresponding to "doubtful" $A$. viridans. This profile reflected positive reactions for hydrolysis of esculin and pyrrolidonyl-2-naphthylamide and acidification of lactose, trehalose, starch, and glycogen. Although the phenotypic traits of the isolates most closely resembled those of aerococci (pyrrolidonyl-2-naphthylamide positive and leucine aminopeptidase negative), their lipophilic nature, variable growth in $6.5 \% \mathrm{NaCl}$, and lack of a preference for aerobic incubation atmospheres distinguished them from typical aerococci. These isolates can be differentiated from streptococci and most other nonaerococcal genera of catalase-negative gram-positive cocci by their inability to produce leucine aminopeptidase. Other leucine aminopeptidasenegative organisms include leuconostocs, distinguished by their resistance to vancomycin, and some gemellae, which fail to hydrolyze esculin, in contrast to the aerococcus-like strains described here. Thermal denaturation experiments on chromosomal DNA from two of the isolates (no. 7 and 22) gave a $\mathrm{G}+\mathrm{C}$ content of 29.5 to $30 \mathrm{~mol} \%$. This DNA base composition value is significantly lower than those reported for aerococci (ca. 35 to $40 \mathrm{~mol} \%$ [19]), gemellae (33 mol\% [8]), and most streptococci (ca. 34 to $46 \mathrm{~mol} \%$ [14]).

The partial 16S rRNA gene sequences of three of the unknown strains were investigated to determine the strains' relationship to other low-G+C-content gram-positive bacteria. The 16S rRNA gene sequence of strain 22 , determined by direct polymerase chain reaction DNA sequencing, is shown in Fig. 1. The sequence consisted of a continuous stretch of 1,464 nucleotides, representing approximately $96 \%$ of the total $16 \mathrm{~S}$ rRNA gene. Similarity values were determined for a 1,330-nucleotide region (ranging from positions 107 to 1410 of the $E$. coli numbering system) of this new sequence and homologous sequences of over 40 reference strains from the genera Aerococcus, Gemella, and Streptococcus and other major phylogenetic lines within the 
TABLE 1. Sequence similarities for a 1,340-nucleotide region of $16 \mathrm{~S}$ rRNAs of $H$. kunzii and some other representative low-G+Ccontent gram-positive organisms

\begin{tabular}{|c|c|c|c|c|c|c|c|c|c|c|c|c|c|c|c|c|c|}
\hline \multirow[b]{2}{*}{ Organism and strain } & \multicolumn{17}{|c|}{$\%$ Sequence similarity } \\
\hline & 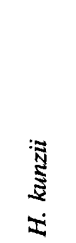 & 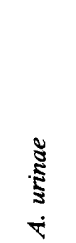 & 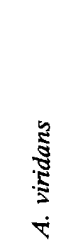 & 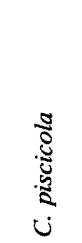 & 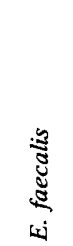 & 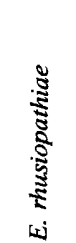 & 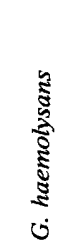 & 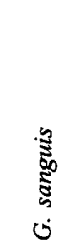 & 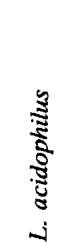 & 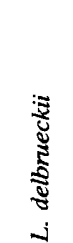 & 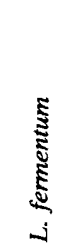 & 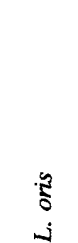 & 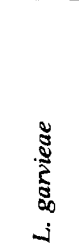 & 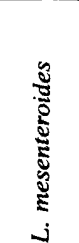 & 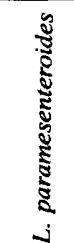 & 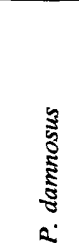 & 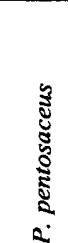 \\
\hline \multicolumn{18}{|l|}{ Helcococcus kunzii NCFB 2900} \\
\hline Aerococcus urinae NCFB 2893 & 79.5 & & & & & & & & & & & & & & & & \\
\hline Aerococcus viridans NCDO 1225 & 80.8 & 94.8 & & & & & & & & & & & & & & & \\
\hline Carnobacterium piscicola NCDO 2762 & 79.7 & 91.4 & 92.0 & & & & & & & & & & & & & & \\
\hline Enterococcus faecalis NCDO 581 & 79.4 & 90.2 & 91.6 & 93.4 & & & & & & & & & & & & & \\
\hline Erysipelothrix rhusiopathiae NCTC 8163 & 77.3 & 82.5 & 83.3 & 82.3 & 81.7 & & & & & & & & & & & & \\
\hline Gemella haemolysans NCTC 10243 & 79.1 & 87.3 & 88.0 & 87.2 & 86.2 & 82.3 & & & & & & & & & & & \\
\hline Globicatella sanguis NCFB 2835 & 80.0 & 90.9 & 91.1 & 91.4 & 91.0 & 83.7 & 87.4 & & & & & & & & & & \\
\hline Lactobacillus acidophilus NCDO 1748 & 79.4 & 87.9 & 87.2 & 87.8 & 88.1 & 81.0 & 84.6 & 88.1 & & & & & & & & & \\
\hline Lactobacillus delbrueckii NCDO 213 & 79.3 & 86.7 & 87.4 & 87.3 & 87.5 & 81.7 & 84.3 & 86.9 & 94.2 & & & & & & & & \\
\hline Lactobacillus fermentum NCDO 1750 & 78.7 & 90.2 & 90.2 & 89.9 & 88.7 & 81.5 & 84.7 & 88.7 & 89.8 & 89.2 & & & & & & & \\
\hline Lactobacillus oris NCDO 2160 & 78.8 & 88.4 & 88.6 & 89.0 & 88.6 & 82.3 & 84.6 & 89.1 & 90.2 & 89.2 & 93.8 & & & & & & \\
\hline Lactococcus garvieae NCDO 2155 & 79.5 & 86.1 & 87.7 & 87.6 & 86.8 & 81.9 & 85.1 & 88.4 & 85.0 & 85.8 & 86.6 & 86.5 & & & & & \\
\hline Leuconostoc mesenteroides NCDO 523 & 78.1 & 86.7 & 87.6 & 85.7 & 86.4 & 81.6 & 83.1 & 86.3 & 86.6 & 86.0 & 87.0 & 87.3 & 84.6 & & & & \\
\hline $\begin{array}{l}\text { Leuconostoc paramesenteroides } \\
\text { NCDO } 803\end{array}$ & 79.8 & 88.4 & 89.5 & 89.5 & 88.7 & 81.9 & 84.7 & 89.0 & 87.6 & 87.0 & 89.7 & 90.5 & 86.8 & 91.0 & & & \\
\hline Pediococcus damnosus NCDO 832 & 79.7 & 89.6 & 90.2 & 92.0 & 90.5 & 82.7 & 86.3 & 89.9 & 89.7 & 89.3 & 92.6 & 92.3 & 87.8 & 87.0 & 89.9 & & \\
\hline Pediococcus pentosaceus NCDO 990 & 79.1 & 89.6 & 89.7 & 91.9 & 90.0 & 82.7 & 86.0 & 89.9 & 89.3 & 88.7 & 92.4 & 92.6 & 88.1 & 86.7 & 89.5 & 96.6 & \\
\hline Streptococcus agalactiae NCDO 1348 & 79.9 & 87.7 & 88.1 & 89.3 & 89.4 & 82.9 & 85.9 & 88.3 & 85.7 & 85.5 & 86.1 & 86.5 & 90.3 & 85.5 & 87.2 & 88.2 & 88.8 \\
\hline
\end{tabular}

lactic acid bacteria. Approximately 100 nucleotides proximal to the $5^{\prime}$ end of the rRNA gene were omitted from the similarity calculations in order to remove alignment problems arising from considerable variations between species in the length of the V1 variable region (see the work of Neefs et al. [17] for nomenclature). A matrix of representative sequence similarities is shown in Table 1 . Isolate 22 exhibited very low levels of sequence similarity with aerococci, gemellae, streptococci, and related species (ca. 77 to $82 \%$ ). In view of this remote relationship to the lactic acid and related bacteria, the comparative analysis was extended to include other low-G+C-content gram-positive sequences available in the EMBL data base. Isolate 22 displayed only distant relationships ( $<80 \%$ similarity) to all the organisms examined (including mycoplasmas), thereby confirming its genealogical distinctiveness. A phylogenetic tree depicting the position of the unknown bacterium within a radiation of low-G+C-content gram-positive bacteria is shown in Fig. 2. Fragments (ca. positions 7 to 530, which includes the diagnostic variable regions $\mathrm{V} 1$ and $\mathrm{V} 2$ ) of the $16 \mathrm{~S}$ rRNA genes of two further isolates (no. 7 and 14) were also investigated and found to be identical to that of strain 22 , consistent with the high degree of biochemical uniformity shown among the clinical isolates. Furthermore, chromosomal DNA-pairing studies revealed $75 \%$ homology between isolates 7 and 22 , consistent with the isolates' belonging to a single species.

We have phenotypically characterized nine catalase-negative, facultatively anaerobic cocci isolated from human wound infections. On the basis of their overall biochemical profiles, the strains resemble aerococci but can be distinguished from them by their lipophilic nature. Comparative 16S rRNA sequence analyses clearly demonstrate that the clinical isolates from human sources are phylogenetically only remotely related to aerococci, streptococci, and other catalase-negative, facultatively anaerobic, low-G+C-content gram-positive taxa. In view of the presented phylogenetic evidence and the phenotypic distinctiveness of these unknown clinical isolates, it is proposed that they be classified in a new genus, Helcococcus, as Helcococcus kunzii sp. nov.

Description of Helcococcus gen. nov. Helcococcus (Hel.co. coc'cus. Gr. n. helkos, wound; Gr. mas. n. coccus, berry, sphere; N.L. mas. n. Helcococcus, a sphere found in wounds). Cells consist of gram-positive cocci and are nonmotile. Catalase negative. Facultatively anaerobic. Acid but not gas is produced from glucose and some other sugars. Lactate and acetate are the major end products of glucose metabolism. Growth may or may not occur in $6.5 \% \mathrm{NaCl}$. No growth on bile-esculin agar. Lipophilic (growth greatly stimulated by serum or Tween 80 ). Pyrrolidonylarylamidase positive. Arginine dehydrolase and leucine arylamidase negative. Susceptible to vancomycin. The $\mathrm{G}+\mathrm{C}$ content of DNA is 29.5 to $30 \mathrm{~mol} \%$. The type species is Helcococcus kunzii.

Description of Helcococcus kunzii sp. nov. Helcococcus kunzii (kunzi.i. M.L. gen. n. kunzii, named after Lawrence J. Kunz, an American bacteriologist). Cells are nonpigmented and nonmotile. Nonhemolytic. Growth may or may not occur in $6.5 \% \mathrm{NaCl}$. No growth on bile-esculin agar. Lipophilic. Catalase negative. Facultatively anaerobic. Acid is produced from lactose and trehalose; some strains produce acid from glycogen. Acid is not produced from arabinose, inulin, raffinose, ribose, or sorbitol. Esculin is hydrolyzed in the API test system as well as the conventional test system; starch is hydrolyzed in the API test system but not in the conventional Centers for Disease Control test system. Gelatin, hippurate, and urea are not hydrolyzed. Arginine is not deaminated. Pyrrolidonylarylamidase positive. Some strains produce pyrazinamidase. Alkaline phosphatase, $\alpha$-galactosi- 


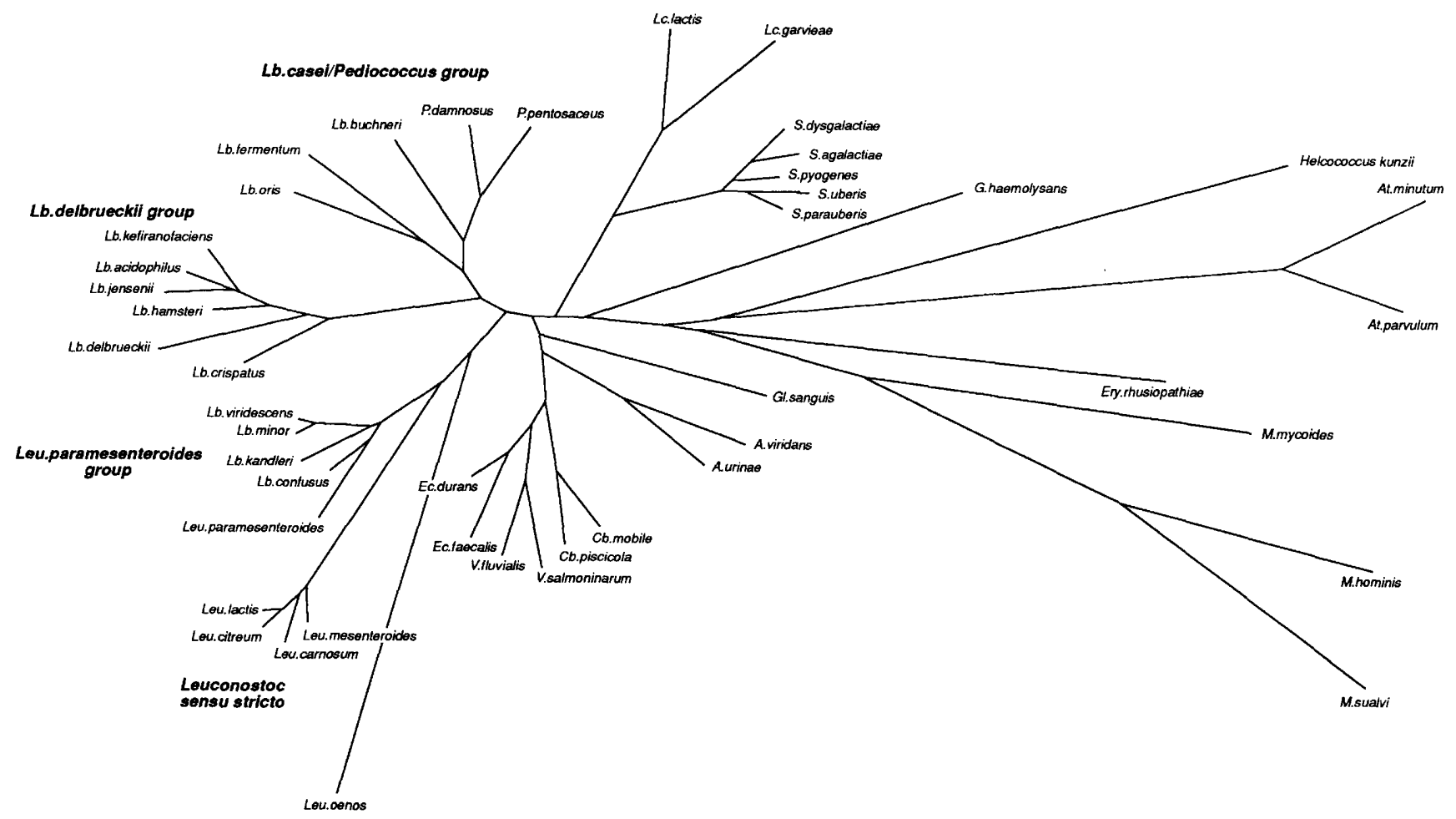

FIG. 2. Unrooted tree, based on a comparison of ca. 1,330 nucleotides, showing the phylogenetic interrelationships of $H$. kunzii and some other low-G+C-content gram-positive bacteria. Abbreviations: A., Aerococcus; At., Atopobium; Cb., Carnobacterium; Ec., Enterococcus; Ery., Erysipelothrix; G., Gemella; Gl., Globicatella; Lb., Lactobacillus; Lc., Lactococcus; Leu., Leuconostoc; M., Mycoplasma; P., Pediococcus; S., Streptococcus; V., Vagococcus.

dase, $\beta$-galactosidase, $\beta$-glucuronidase, and leucine arylamidase negative. Voges-Proskauer negative. Nitrate is not reduced. Vancomycin sensitive. The $\mathrm{G}+\mathrm{C}$ content of DNA of the type strain is $30 \mathrm{~mol} \%$, as determined by melting temperature. Isolated from human sources (foot wounds, leg ulcers, purulent breast mass). The type strain is NCFB 2900 $(=$ no. 22$)$.

\section{ACKNOWLEDGMENTS}

M.D.C. and U.M.R. are grateful to the Ministry of Agriculture, Food, and Fisheries for their financial support.

We thank T. O. MacAdoo (Virginia Polytechnic Institute and State University, Blacksburg) for the derivation of the generic name.

\section{REFERENCES}

1. Aguirre, M., and M. D. Collins. 1992. Phylogenetic analysis of some Aerococcus-like organisms from urinary tract infections: description of Aerococcus urinae sp. nov. J. Gen. Microbiol. 138:401-405.

2. Bentley, R. W., J. A. Leigh, and M. D. Collins. 1991. Intrageneric structure of Streptococcus based on comparative analysis of small-subunit rRNA sequences. Int. J. Syst. Bacteriol. 41: 487-494.

3. Collins, M. D., C. Ash, J. A. E. Farrow, S. Wallbanks, and A. M. Williams. 1989. 16S ribosomal ribonucleic acid sequence analyses of lactococci and related taxa. Description of Vagococcus fluvialis gen. nov., sp. nov. J. Appl. Bacteriol. 67:453-460.

4. Collins, M. D., U. Rodrigues, C. Ash, M. Aguirre, J. A. E. Farrow, A. Martinez-Murcia, B. A. Phillips, A. M. Williams, and S. Wallbanks. 1991. Phylogenetic analysis of the genus Lactobacillus and related lactic acid bacteria as determined by reverse transcriptase sequencing of 16S rRNA. FEMS Micro- biol. Lett. 77:5-12.

5. Collins, M. D., U. M. Rodrigues, N. E. Pigott, and R. R. Facklam. 1991. Enterococcus dispar sp. nov., a new Enterococcus species from human sources. Lett. Appl. Microbiol. 12:9598.

6. Collins, M. D., A. M. Williams, and S. Wallbanks. 1990. The phylogeny of Aerococcus and Pediococcus as determined by 16S rRNA sequence analysis. Description of Tetragenococcus gen. nov. FEMS Microbiol. Lett. 70:255-262.

7. Devereux, J., P. Haeberli, and O. Smithies. 1984. A comprehensive set of sequence analysis programs for the VAX. Nucleic Acids Res. 12:387-395.

8. Evans, J. B. 1986. Genus Aerococcus Williams, Hirch and Cowan $1953,475^{\mathrm{AL}}$, p. 1080 . In P. H. A. Sneath, N. S. Mair, M. E. Sharpe, and J. G. Holt (ed.), Bergey's manual of systematic bacteriology, vol. 2. Williams \& Wilkins, Baltimore.

9. Facklam, R. R., and M. D. Collins. 1989. Identification of Enterococcus species isolated from human infections by a conventional test scheme. J. Clin. Microbiol. 27:731-734.

10. Farrow, J. A. E., D. Jones, B. A. Phillips, and M. D. Collins. 1983. Taxonomic studies on some group D streptococci. J. Gen. Microbiol. 129:1423-1432.

11. Felsenstein, J. 1982. Numerical methods for inferring evolutionary trees. Q. Rev. Biol. 57:379-404.

12. Fitch, W. M., and E. Margoliash. 1967. Construction of phylogenetic trees: a method based on mutation distances as estimated from cytochrome c sequences is of general applicability. Science 155:279-284.

13. Garvie, E. I. 1978. Streptococcus raffinolactis Orla-Jensen and Hansen, a group $\mathrm{N}$ streptococcus found in raw milk. Int. J. Syst. Bacteriol. 28:190-193.

14. Hardie, J. M. 1986. Genus Streptococcus Rosenbach 1884 , $22^{A L}$, p. 1043-1047. In P. H. A. Sneath, N. S. Mair, M. E. Sharpe, and J. G. Holt (ed.), Bergey's manual of systematic bacteriology, vol. 2. Williams \& Wilkins, Baltimore. 
15. Hutson, R. A., D. E. Thompson, and M. D. Collins. 1993. Genetic interrelationships of saccharolytic Clostridium botulinum types B, E and F and related clostridia as revealed by small-subunit rRNA gene sequences. FEMS Microbiol. Lett. 108:103-110.

16. National Committee for Clinical Laboratory Standards. 1990. Performance standards for antimicrobial disk susceptibility tests, 4th ed. Publication M2-A4. National Committee for Clinical Laboratory Standards, Villanova, $\mathrm{Pa}$.

17. Neefs, J. M., Y. Van de Peer, L. Hendriks, and R. De Wachter. 1990. Compilation of small ribosomal subunit RNA sequences. Nucleic Acids Res. 18:2237-2242.

18. Pitcher, D. G., N. A. Saunders, and R. J. Owen. 1989. Rapid extraction of bacterial genomic DNA with guanidium thiocyanate. Lett. Appl. Microbiol. 8:151-156.

19. Reyn, A. 1986. Genus Gemella Berger $1960,253^{\mathrm{AL}}$, p. 1081 1082. In P. H. A. Sneath, N. S. Mair, M. E. Sharpe, and J. G. Holt (ed.), Bergey's manual of systematic bacteriology, vol. 2. Williams \& Wilkins, Baltimore.

20. Sulea, I. T., M. C. Pollice, and L. Barksdale. 1980. Pyrazine carboxylamidase activity in Corynebacterium. Int. J. Syst. Bacteriol. 30:466-472.
21. Wallbanks, S., A. J. Martinez-Murcia, J. L. Fryer, B. A. Phillips, and M. D. Collins. 1990. 16S rRNA sequence determination for members of the genus Carnobacterium and related lactic acid bacteria and description of Vagococcus salmoninarum sp. nov. Int. J. Syst. Bacteriol. 40:224-230.

22. Whiley, R. A., H. Y. Fraser, C. W. I. Douglas, J. M. Hardie, A. M. Williams, and M. D. Collins. 1990. Streptococcus parasanguis sp. nov., an atypical viridans Streptococcus from human clinical specimens. FEMS Microbiol. Lett. 68:115-122.

23. Williams, A. M., J. L. Fryer, and M. D. Collins. 1990. Lactococcus piscium sp. nov., a new Lactococcus species from salmonid fish. FEMS Microbiol. Lett. 68:109-114.

24. Williams, A. M., U. M. Rodrigues, and M. D. Collins. 1991. Intrageneric relationships of enterococci as determined by reverse transcriptase sequencing of small-subunit rRNA. Res. Microbiol. 142:67-74.

25. Woese, C. R. 1987. Bacterial evolution. Microbiol. Rev. 51:221271.

26. Wong, J. D. 1987. Porphyrin test as an alternative to benzidine test for detecting cytochromes in catalase-negative gram-positive cocci. J. Clin. Microbiol. 25:2006-2007. 